\title{
Nitrous oxide CryoBalloon therapy of refractory gastric antral vascular ectasia
}

A 69-year-old man with end-stage renal disease on hemodialysis was referred for persistent gastric antral vascular ectasia (GAVE) that required biweekly transfusions. The patient had undergone four endoscopies and treatment with argon plasma coagulation (APC), with no clinical improvement; he was still requiring blood transfusions. Given that the patient was refractory to APC therapy, he was referred for alternative endoscopic therapy.

Given our previous successful experience with cryotherapy, the decision was made to treat the patient with balloon-based nitrous oxide cryotherapy (C2 CryoBalIoon Focal Ablation System; C2 Therapeutics, Redwood City, California, USA). The benefit of this approach is that the balloon allows for self-venting of nitrous oxide and thus reduces the risk of perforation. Anecdotally, patients have less pain compared with APC or radiofrequency ablation. In addition, visibility of the treated area is maintained throughout the entire procedure, and not obscured by frost formation.

A single-channel therapeutic scope was used to treat the GAVE ( $\triangleright$ Fig. 1) in a four-quadrant fashion, ablating the antrum ( $\vee$ Fig. 2, $\triangleright$ Video 1 ). The patient

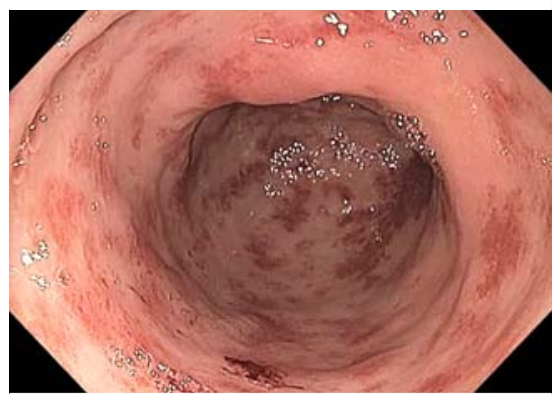

- Fig. 1 Endoscopic image of the gastric antral vascular ectasia prior to treatment. tolerated the procedure well without pain.

At 1-month clinical follow-up, the patient was no longer requiring blood transfusions. At the 3-month endoscopy follow-up, there was mild residual GAVE, but the vast majority had been eradicated (> Fig. 3).

This case demonstrates that CryoBalloon cryotherapy is a feasible option to treat GAVE. To our knowledge, there are limited data on balloon-based nitrous oxide cryotherapy; this is the first reported case in the literature. Large series are needed to confirm our finding.

Endoscopy_UCTN_Code_TTT_1AO_2AD

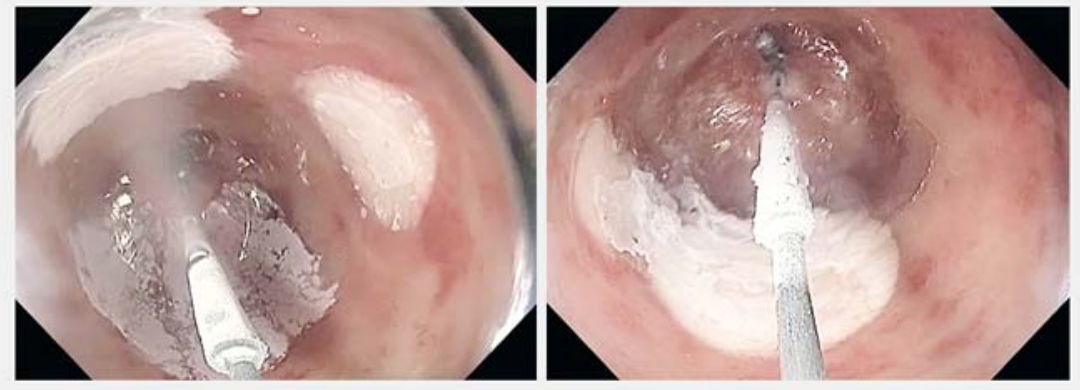

- Fig. 2 Endoscopic images of the gastric antral vascular ectasia being treated with CryoBalloon cryotherapy.

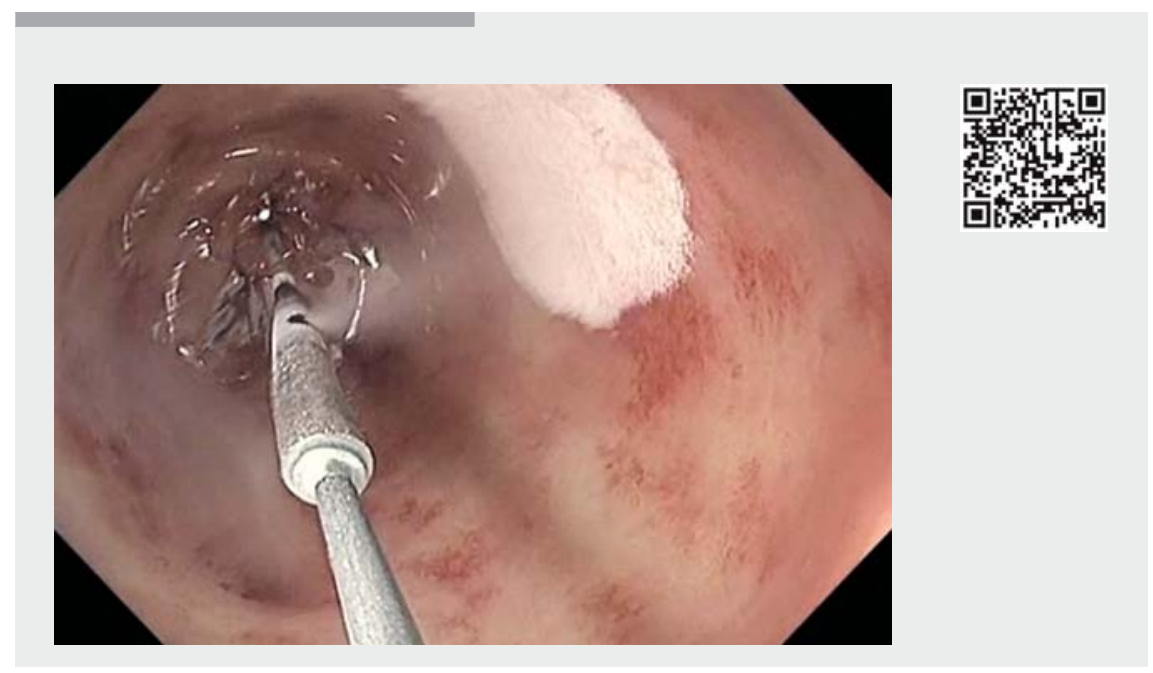

Video 1 CryoBalloon cryotherapy of gastric antral vascular ectasia. 


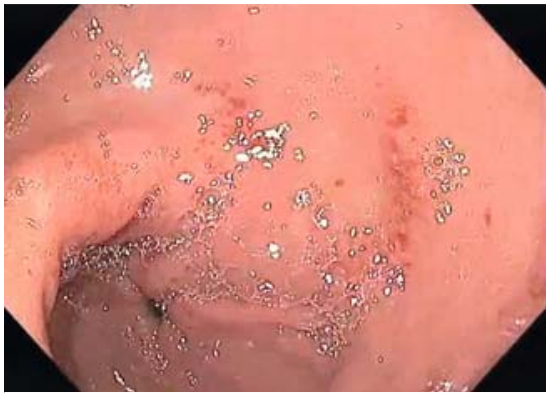

Fig. 3 Follow-up endoscopic image 3 months after cryotherapy, showing eradication of the majority of the gastric antral vascular ectasia.
Competing interests

A. J. T. has received professional fees from C2 Therapeutics.

The Authors

Arvind J. Trindade, Sumant Inamdar, Divyesh V. Sejpal

Hofstra Northwell School of Medicine, Northwell Health System, Division of Gastroenterology, Long Island Jewish Medical Center, New Hyde Park, New York, United States

\section{Corresponding author}

\section{Arvind J. Trindade, MD}

Hofstra Northwell School of Medicine, Northwell Health System, Division of Gastroenterology, Long Island Jewish Medical Center, 270-05 76th Avenue, New Hyde Park, NY 11040, United States Fax: +1-718-470-5509

arvind.trindade@gmail.com

\section{Bibliography}

DOI https://doi.org/10.1055/s-0043-111009

Published online: 5.7.2017

Endoscopy 2017; 49: 923-924

(c) Georg Thieme Verlag KG

Stuttgart · New York

ISSN 0013-726X

\section{ENDOSCOPY E-VIDEOS}

https:/|eref.thieme.de/e-videos

口回 Endoscopy E-Videos is a free

access online section, reporting

靣社: on interesting cases and new techniques in gastroenterological endoscopy. All papers include a high quality video and all contributions are freely accessible online.

This section has its own submission website at https://mc.manuscriptcentral.com/e-videos 